\title{
COMPREENSÃO DE ADOLESCENTES DE UMA ESCOLA PÚBLICA DE GURUPI- TOCANTINS SOBRE SAÚDE E AS FONTES DE INFORMAÇÃO
}

\section{ADOLESCENTS UNDERSTANDING FROM A PUBLIC SCHOOL OF GURUPI-TOCANTINS OF THE HEALTH CARE AND THEIR SOURCES OF INFORMATION}

Meirylaine Pereira Bezerra Viegas ${ }^{1}$, Marta Azevedo dos Santos ${ }^{2,}$ Victor Rodrigues Nepomuceno ${ }^{3}$.

\section{RESUMO}

Introdução: A informação é fundamental para a Promoção da Saúde junto aos adolescentes, pois contribui com o empoderamento do sujeito e da comunidade. Objetivos: Compreender a percepção dos adolescentes matriculados no $9^{\circ}$ ano de uma Escola Municipal de Gurupi-Tocantins sobre saúde e as fontes que fornecem essa informação. Metodologia: Pesquisa descritiva e exploratória, de abordagem qualitativa. Participaram 6 (seis) alunos matriculados no $9^{\circ}$ ano de uma Escola Municipal de Gurupi-TO. A coleta de dados ocorreu por meio de entrevista com base em um questionário semiestruturado. Para a análise dos dados utilizou-se o método de análise de conteúdo. Resultados e discussão: A compreensão sobre saúde remeteu ao modelo biomédico. As principais fontes de informação citadas foram a família, a escola, amigos e meios de comunicação, especialmente a televisão e a internet. Os adolescentes confiam nos profissionais da Unidade Básica de Saúde, porém não compreendem com clareza as informações que recebem. Conclusões: a compreensão sobre saúde não contemplou os múltiplos aspectos relacionados aos Determinantes Sociais em Saúde. Existe a necessidade de projetos de Educação em Saúde que envolvam os estudantes no desenvolvimento de ações direcionadas a esse público na própria escola.

Palavras-chave: Saúde do Adolescente; Educação em Saúde; Comunicação em Saúde; Saúde Escolar; Ações Intersetoriais.

\section{ABSTRACT}

Introduction: Information is crucial for promoting health care, as it contributes to the empowerment of the community as well as the subject. Objectives: To understand the teenagers - enrolled in the 9th grade of a Municipal School of Gurupi, Tocantins (TO), Brazil - perception of the health care and the sources that provide them information. Methodology: It is a descriptive exploratory research, and the approach is qualitative. Six (6) students, enrolled in the 9th grade of a Municipal School of Gurupi, TO, participated in the survey. Data were collected through an interview based on a semistructured questionnaire. The method used for analyzing the data was the content analysis. Results and discussion: Adolescents' understanding of health care refers to the biomedical model. The main sources of health care information they mentioned were their family, school, friends and the media, especially television and the internet. Adolescents rely on the professionals of the basic health care centers, but they do not clearly understand the information they receive. Conclusions: the understanding about of health care does not consider the multiple aspects that involve health care, having as reference the perspective of the Social Determinants of Health Care. Henceforth, there is a need for Health Care Education projects that involve the students in the development of actions addressed to this public, which can be developed in the school.

Keywords: Health Care of Adolescents; Health Care Education; Health Care Communication; School Health Care; Interdepartmental Actions.
1 Psicóloga. Mestre em Ciências da Saúde pela Universidade Federal do Tocantins (UFT). Jornalista da Assessoria de Comunicação da Universidade de Gurupi. E-mail: meirybezerra@gmail.com

Doutora em Psicologia pela Universidade Federal de Sevilla ES. Professora do Programa de Mestrado Profissional em Ciências da Saúde da Universidade Federal do Tocantins. E-mail: marta@uft.edu.br.

Doutor em Ciências pela Universidade de São Paulo Ribeirão Preto - USP. Docente do Programa de Pós-graduação em Ciências da Saúde da Universidade Federal do Tocantins. E-mail: victorn@mail.uft.edu.br 


\section{INTRODUÇAO}

O Estatuto da Juventude, conforme a Lei ํㅜ 12.852, de 5 de agosto de 2013, define os indivíduos com idade entre 15 e 17 anos como sendo adolescentes-jovens e de 18 a 24 anos, como jovens-jovens (BRASIL, 2013a).

Os direitos das crianças e dos adolescentes foram legalmente assegurados na Constituição Federal de 1988, no Estatuto da Criança e do Adolescente (ECA - 1990) e ainda pela Convenção Internacional sobre os Direitos da Criança (1989) - ratificada pelo Brasil em 1990. O ECA considera que a criança é a pessoa com até 12 anos de idade incompletos, e adolescente aquela entre doze e dezoito anos de idade (BRASIL, 1990). Já o Ministério da Saúde (MS) acompanha a Organização Mundial de Saúde (OMS) ao considerar o adolescente como o indivíduo com idade entre 10 e 19 anos, 11 meses e 29 dias.

Além do critério cronológico, condições biológicas, psicológicas, e sociais também devem ser consideradas na abordagem que envolve a adolescência e a juventude, observando a individualidade dos sujeitos (BRASIL, 2007b).

A atenção ao adolescente é foco de políticas públicas no Brasil, envolvendo os diferentes setores, que buscam compreender os adolescentes em seus diversos contextos (BRASIL, 2010). Entre tais políticas estão aquelas que são direcionadas à saúde do adolescente. A saúde é compreendida como uma complexa rede não-linear em que há a interdependência de múltiplos fatores, entre biológicos, ambientais, estilo de vida e o acesso aos serviços de saúde, chamados de determinantes sociais de saúde (GOSCH, 2013).

$\mathrm{Na}$ abordagem da saúde do adolescente, o acesso desse público aos serviços de saúde é um aspecto relevante. De acordo com a Pesquisa Nacional de Saúde Escolar (Pense $)^{1,}$ em 2015, 55,3\% dos estudantes do $9^{\circ}$ ano do ensino fundamental recorreram a algum profissional ou unidade de saúde do País. O percentual é $14,8 \%$ maior que os dados da mesma pesquisa realizada em 2012 (48,2\%). Entre os serviços mais buscados, 45,1\% afirmaram ter ido a uma Unidade Básica de Saúde (UBS) e 22,8\% procuraram atendimento em consultórios médicos ou clínicas particulares.

A mobilização da população e a adoção de comportamentos em prol da saúde são fatores relevantes, que estão relacionados ao conhecimento a respeito da saúde e dos

\footnotetext{
${ }^{1}$ Disponível em https://biblioteca.ibge.gov.br/visualizacao/livros/liv97870.pdf
} 
seus determinantes. Entre outros aspectos, isso passa pelo acesso a informação sobre o tema, proveniente de diversas fontes que um indivíduo tem acesso ao longo da vida.

Desde o Movimento da Reforma Sanitária, a comunicação - envolvendo saberes, práticas e processos - é um dos importantes instrumentos de realização do projeto de autonomia do cidadão em relação à saúde, fundamentado nas políticas do Sistema Único de Saúde (SUS) (XAVIER, 2006).

O campo Comunicação \& Saúde no Brasil iniciou de forma articulada na década de 1990, com foco na formação de profissionais, fomento de pesquisas e estímulo ao debate em espaços como as Conferências Nacionais de Saúde (CNS). Mas anos antes, na VIII CNS, em 1986, emergiu o discurso sobre o direito à informação, educação e comunicação como inerentes ao direito à saúde (ARAUJO; CARDOSO, 2007).

Em uma sociedade permeada pelo acesso crescente aos meios de comunicação, a produção de conteúdos informativos no âmbito da saúde é uma estratégia adotada por órgãos governamentais. No contexto brasileiro, o Ministério da Saúde (MS) tem a proposta de informar a população em geral sobre as diretrizes do SUS e políticas de saúde, ao mesmo tempo em que busca ampliar a participação popular e o controle social (BRASIL, 2006).

As informações sobre saúde também circulam em outros ambientes, como nas escolas, em unidades de saúde, em ambientes familiares e em outros espaços concretos de convívio do adolescente. Todavia, a informação circulante atualmente não é originada somente em fontes tidas como oficiais, tais como o MS, outros órgãos governamentais, ou entidades que representam determinadas categorias de profissionais da saúde, tais como Conselhos Federais, Sociedades Brasileiras, Associações entre outros.

Nesse sentido, essa pesquisa que surgiu do desejo de conhecer as fontes de informação que os adolescentes buscam sobre saúde, na cidade de Gurupi-Tocantins, teve como objetivo geral, compreender a percepção dos adolescentes sobre saúde e sobre as fontes que fornecem essa informação,

\section{MATERIAIS E METODOS}

Trata-se de uma pesquisa de natureza qualitativa, descritiva e exploratória.

A pesquisa qualitativa aborda essencialmente os significados, motivos, aspirações, crenças, valores e atitudes, correspondendo assim "a um território mais profundo das relações, dos processos e dos fenômenos que não podem ser reduzidos à operacionalização de variáveis" (MINAYO, 2001, p.22) 
Os sujeitos da pesquisa foram estudantes voluntários matriculados no $9^{\circ}$ ano de uma Escola Municipal, em Gurupi-Tocantins. A unidade escolar em que a pesquisa foi realizada, de janeiro a março de 2018 foi definida por meio de sorteio, entre as cinco escolas que ofertaram o $9^{\circ}$ ano no primeiro semestre letivo do ano de 2018 , conforme uma consulta realizada à Secretaria Municipal de Educação de Gurupi, em janeiro de 2018, a qual autorizou a realização da pesquisa. Nessa unidade escolar havia quatro turmas de $9^{\circ}$ ano, por isso, também foi realizado um sorteio para escolha de uma turma, sendo escolhida a turma denominada nesse trabalho como turma " $A$ ".

Optou-se por fazer a coleta de dados com estudantes do $9^{\circ}$ ano do Ensino Fundamental, tendo como base a idade dos alunos matriculados nessa série, que compreende a faixa-etária definida pela OMS como adolescente.

Os critérios de inclusão adotados foram: estudantes com idade entre 10 e 19 anos, de ambos os sexos, matriculados na turma de $9^{\circ}$ ano "A" de uma Escola Municipal do município de Gurupi-Tocantins, que se propuseram a realizar a entrevista. Os critérios de exclusão foram: alunos que não manifestaram interesse de forma voluntária para participação na pesquisa e ainda os que não apresentaram o Termo de Livre Consentimento e Esclarecido (TCLE) preenchido e assinado pelos pais ou responsáveis.

Após a aprovação do Comitê de Ética em Pesquisa com Seres Humanos do Centro Universitário UnirG (sob CAAE: 80637517.4.0000.5518 e aprovado em acordo com o parecer $n^{\circ}$ 2.425.716), o projeto foi apresentado ao diretor da escola, em janeiro de 2018 . Quando as aulas foram iniciadas, o trabalho foi apresentado aos estudantes da turma selecionada, em um dia letivo do mês de março de 2018, quando havia a presença de 25 (vinte e cinco) estudantes. Em conformidade com o projeto submetido ao referido Comitê de Ética, as informações relacionadas à identidade dos estudantes ou identificação da escola foram preservadas, não havendo assim a divulgação do nome da Unidade Escolar.

O projeto foi apresentado aos alunos com a utilização de projeção de material visual em que constavam os objetivos, etapas, riscos e benefícios da pesquisa, além de orientações para preenchimento do TCLE. De um universo de 25 (vinte e cinco) alunos, após a aplicação dos critérios de exclusão mencionados anteriormente, participaram da pesquisa 6 (seis estudantes).

A pesquisa foi realizada conforme prevê a resolução 466/2012 do Conselho Nacional de Saúde. A coleta de dados foi realizada feita por meio de entrevista individual, em março de 2018, a partir de um roteiro semiestruturado, na sala da biblioteca da escola, em datas e horários previamente marcados com a direção da unidade. 
Ao iniciar as entrevistas, novamente foram feitos esclarecimentos quanto aos objetivos, etapas, benefícios, riscos e os procedimentos adotados durante a pesquisa. A qual, conforme roteiro semiestruturado, foi gravada em equipamento adequados para captação de áudio em formato MP3 (gravador).

As entrevistas foram transcritas integralmente e analisadas conforme a técnica de análise de conteúdo, a qual consiste em um conjunto de técnicas de análises de comunicações com o propósito de obter por meio de procedimentos objetivos e sistemáticos de descrição do conteúdo de mensagens, indicadores que possibilitam a inferência de conhecimentos a respeito às condições de produção/recepção (variáveis inferidas) dessas mensagens. (BARDIN, 2011).

A análise foi realizada em três fases: pré-análise, que consistiu na organização das ideias inicias, formulação de hipóteses por meio da leitura "flutuante" do material escolhido, ou seja, a transcrição das entrevistas realizadas com alunos do 9 ำ ano de uma escola municipal de Gurupi-Tocantins. Na etapa da exploração do material foi feita a leitura exaustiva e a definição das categorias de análise. Os resultados foram organizados em tabelas de classificação das unidades de contexto e unidades de registro.

\section{RESULTADOS E DISCUSSÃO}

O perfil dos voluntários entrevistados que participaram da pesquisa foi identificado conforme a tabela 1. A identidade de cada participante foi preservada, sendo as falas de cada sujeito serão identificadas pela letra "E", referindo-se a "entrevistado".

Tabela 1 - Perfil dos estudantes matriculados no 9a ano de uma escola municipal de Gurupi-Tocantins.

\begin{tabular}{llll}
\hline Entrevistado & Idade & Sexo & Tempo que estuda na escola \\
\hline E1 & 13 & $\mathrm{~F}$ & 2 anos e 1 mês \\
E2 & 13 & $\mathrm{M}$ & Mais de 3 anos \\
E3 & 14 & $\mathrm{~F}$ & $\backslash 9$ anos \\
E4 & 15 & $\mathrm{M}$ & Mais de 4 anos \\
E5 & 15 & $\mathrm{~F}$ & $\backslash 4$ anos \\
E6 & 13 & $\mathrm{~F}$ & 13 anos \\
\hline
\end{tabular}

Fonte: autora da pesquisa, a partir de dados extraídos de entrevistas realizadas com alunos do $9^{\circ}$ ano do Ensino Fundamental

Conforme os dados apresentados na tabela, o fato de que os alunos não mudaram de escola nos últimos anos é relevante, tendo em vista que esse grupo de estudantes teria condições de apresentar informações sobre possíveis ações de saúde no âmbito da escola, não apenas em relação ao ano anterior, mas também em 2 ou mais anos letivos 
anteriores. Com o propósito de responder aos objetivos da pesquisa foi realizada a análise categorial. Foram utilizadas unidades de registro por meio de uma análise temática, buscando os núcleos de sentido presentes nas falas dos entrevistados. Em seguida, foram definidas as unidades de contexto e as categorias finais de análise de conteúdo conforme quadro abaixo:

Tabela 2 - Categorias finais de análise de conteúdo

\begin{tabular}{ll}
\hline Categoria & Descrição \\
\hline Categoria I & Compreensão de saúde \\
Categoria II & Fontes de informação sobre saúde \\
Categoria III & Utilização dos serviços de saúde na comunidade \\
Categoria IV & Confiança e compreensão das informações recebidas \\
Categoria V & Autoavaliação do nível de conhecimento sobre saúde \\
\hline
\end{tabular}

Fonte: autora da pesquisa, a partir de dados extraídos de entrevistas realizadas com alunos do $9^{\circ}$ ano do Ensino Fundamental

\section{-Categoria I: Compreensão sobre saúde}

Ao serem questionados sobre a compreensão de saúde, três entrevistados responderam:

"Acho que é ter o corpo melhor, cuidar do corpo, sem sentir alguma coisa [...] E também ter uma boa convivência sem sentir algo errado, uma boa alimentação (silêncio). Acho que só” (E2).

“Saúde... é... nosso.... rapaz (risos)...não sei nem o que eu falo...deixa eu ver...saúde é...que tem que cuidar, preservar e fazer consulta, esses trem, pra o dia-a-dia da gente ficar melhor" (E5).

"Saúde pra mim significa o bem-estar da pessoa. Ter uma boa alimentação, escovar bem os dentes pra não ficar com mau hálito...(silêncio)...não sei" (E6).

A compreensão de saúde para os adolescentes foi expressa por meio de respostas que remetem a bem-estar, hábitos de higiene, ausência de doença, alimentação e utilização de serviços de saúde. Apresentam também, uma compreensão relacionada a fatores como a boa convivência com outras pessoas.

O conteúdo das entrevistas foi semelhante ao relatado por Sousa; Silva e Ferreira (2014) ao descrever os saberes de adolescentes sobre a saúde, em que a representação 
de saúde para o adolescente esteve associada à boa prática alimentar e ao bem-estar geral do corpo. As autoras reforçam que, ao definirem o que é saúde e como se dá o cuidado com a própria, os adolescentes não percebem a total abrangência que esta possui. Na presente pesquisa, observa-se que essa afirmativa também se confirma, haja vista que a compreensão dos adolescentes entrevistados mostrou certa restrição em relação aos múltiplos fatores que integram a saúde.

Complementando a questão anterior, os adolescentes foram questionados se já tinham ouvido falar sobre saúde ou se já tinham aprendido algum conteúdo sobre saúde. Além das respostas negativas para o conhecimento sobre o assunto, o autocuidado foi citado por um dos entrevistados:

"Que a gente sempre deve se preocupar né, como a gente tá, com cada parte do nosso corpo, a gente precisa saber, se orientar mais sobre a saúde" (E1)

O autocuidado é um dos fundamentos do SUS, que prevê que os serviços de saúde devem funcionar também como promotores da saúde individual e coletiva, reduzindo a dependência da população e ampliando a capacidade de autocuidado e autonomia das pessoas, da sociedade e da escola (BRASIL, 2007a).

\section{Categoria II: Fontes de informação sobre saúde}

Ao falarem sobre o recebimento de informações sobre saúde cotidianamente, todos os entrevistados responderam de forma positiva, citando meios de comunicação (televisão, internet), familiares, amigos, profissionais de saúde e a escola como fontes.

Os entrevistados destacaram ainda o acesso a informações sobre saúde por meio de palestras realizadas na escola, com envolvimento dos profissionais de saúde da Unidade Básica de Saúde (UBS) situada a poucos metros da escola municipal. Também foi citada a atuação desses profissionais fora da escola, nas visitas domiciliares, nas ruas do bairro e na própria UBS.

De acordo com Silva e Bodstein (2016), o ambiente escolar, em especial no sistema público, é um espaço relevante para práticas e vivências em saúde nas relações entre os indivíduos que partilham desse contexto. Aspectos determinantes das condições de saúde e doença podem ser analisados e problematizados a partir do contexto escolar. 
A UBS, possui grande relevância no acesso aos serviços do SUS, tendo em vista que é instalada em territórios próximos aos locais em que as pessoas residem, sendo um local de acolhimento para que o usuário tenha acesso aos serviços de atenção primária do SUS.

Quase todos os entrevistados citaram ter acessos a conteúdos televisivos exibidos diariamente pela Rede Globo de Televisão (Programa Bem-Estar, Jornal Nacional e o informe Dicas de Saúde veiculado na programação da TV Anhanguera, afiliada da Rede Globo no Tocantins). Isso levanta outras indagações, a respeito de qual abordagem é dada pelos grandes grupos de comunicação ao tema saúde, tendo em vista que para grande parte de população, a televisão é meio de comunicação mais utilizado e, portanto, pode contribuir para a formação do conceito que a população possui sobre a temática.

Os entrevistados responderam ainda que cotidianamente preferem utilizar a internet (especialmente no celular) para obtenção de informações e indicaram de que forma a informação chega até eles:

"Procuro em sites, informações. Só digito 'mais informações sobre tais doenças', só isso, e o site sobre alguma coisa que eu queira saber. O que aparecer primeiro eu vejo pra me informar mais". (E1)

"No Facebook mostra esses negócios de doenças, acho que aparece bem. Tipo essas coisas que também estão no YouTube e no Facebook. Mas nunca cliquei lá, quem coisa todo dia esses trem réi de saúde todo dia é minha mãe. Ela pesquisa esses negócios sobre saúde, as doenças”. (E5)

As mídias sociais, como Facebook e plataformas de compartilhamento de vídeos, como o YouTube, especialmente entre adolescentes, agregam em uma mesma atividade, a obtenção de informações das mais diversas naturezas, o prazer e o lazer. Observou-se que na fala dos entrevistados não há indicação de preocupação na escolha das informações que serão acessadas quando optam por fazer uma pesquisa sobre saúde. No contexto midiático, a informação sobre saúde também é vista como mercadoria, por transmitir sentidos e influenciar a audiência para a adoção de comportamentos ou consumo de produtos relacionados à longevidade, qualidade de vida e bem-estar.

As notícias falsas ou mentirosas, conhecidas internacionalmente como fake news, são disseminadas em qualquer meio de comunicação. $\mathrm{Na}$ internet são propagadas velozmente e possuem o intuito de atrair a atenção para desinformar ou obter vantagem política ou econômica (BRAGA, 2018). Essas também são informações que podem 
chegar ao adolescente, sem que o mesmo perceba ou identifique de maneira clara, levando o usuário a uma compreensão equivocada.

Sobre a busca espontânea de informações sobre saúde, os adolescentes responderam que buscam informações quando querem entender alguma alteração ocorrida com eles mesmos ou com alguém da sua família:

"Uma vez minha avó deu AVC e eu não sabia muito bem o que era, as causas e tal, então eu fui procurar, eu me informei muito do que era, do que acontecia" (E1).

Uma pesquisa realizada em 11 países para uma empresa de seguros de saúde indicou que, em comparação a outros 11 países (Austrália, China, EUA, França, Alemanha, Índia, Itália, México, Rússia, Espanha e Reino Unido), o Brasil ficou em quinto lugar no índice de países em que a população mais pesquisa sobre saúde. Os dados mostram que, entre os brasileiros, $68 \%$ fazem consultas na internet sobre medicamentos, 45\% sobre hospitais e $41 \%$ tem a intenção de conhecer experiências de outros pacientes. Porém, $25 \%$ dos entrevistados disseram que não se certificam sobre a confiabilidade da fonte de informação (PASTORE, 2011).

Os seis adolescentes desta pesquisa também descreveram como gostariam que informações sobre saúde fossem divulgadas, com frequentes referências aos meios de comunicação, como a televisão e a internet, confirmando a abrangência entre os jovens. Todavia, a escola e a atuação dos profissionais de saúde em contato com a comunidade (por meio de campanhas, palestras e orientações) é destacada pelos adolescentes como fontes de informações desejadas por eles.

Nessa pesquisa, os adolescentes afirmaram ter cuidado ao acessar ou receber informações na internet, tendo em vista a larga proliferação das fake news.

\section{Categoria III: Utilização dos serviços de saúde na comunidade:}

O adoecimento foi o principal fator motivador para que os adolescentes busquem os serviços de saúde, como explicitado nas falas dos entrevistados:

"Minha mãe manda eu ir me consultar, e eu só procuro médico num caso de emergência mesmo, que eu procuro médico ou alguma coisa, só isso. Quando eu tô bom mesmo, não faço consulta nada, só quando é uma emergência” (E4). 
"De vez em quando vou no postinho, mas é difícil eu ir, só mesmo quando estou precisando de alguma coisa" (E3)

A pesquisa desenvolvida por Vieira et al (2014) também evidenciou que os adolescentes buscam a UBS motivados principalmente pela doença e que eles não se sentem como parte do território do serviço. Reforça que existe uma tendência de predominar entre os adolescentes, o modelo médico assistencialista, o que é um obstáculo à consolidação da atenção integral proposta pela Estratégia de Saúde da Família.

Observa-se também que existe a possibilidade de que adolescentes podem sentir vergonha e medo de serem repreendidos pelo profissional de saúde na UBS, tornando mais difícil o ato de buscarem os serviços de saúde na comunidade espontaneamente. Isso reforça a necessidade de acolhimento adequado ao adolescente, para que eles se sintam encorajado a comparecer à UBS em outras ocasiões, que não apenas para realização de consultas médicas.

\section{Categoria IV: Confiança e compreensão das informações recebidas:}

Ao longo das entrevistas, todos os adolescentes relataram dificuldades em compreender as informações que recebem sobre saúde pelos meios de comunicação.

Sobre as informações recebidas pelos profissionais da UBS, os adolescentes também relataram que é necessária maior clareza na transmissão da informação. Também se observa que os adolescentes não buscam sanar suas dúvidas, quando elas surgem:

"Tem coisas que não ficam claras não, que eu não entendo (...) Eles explicam lá, mas é complicado. Esse negócio de saúde é complicado, eu não entendo não... mas fico com dúvida, não tiro não". (E4)

"No postinho, às vezes, eu fico com dúvidas. Mas também não pergunto. Sei lá, sinto vergonha" (E5)

"Tem coisas que pra mim, às vezes, não ficam muito claras, que eu não entendo" (E6)

Observa-se que mesmo buscando atendimento com profissionais dos órgãos de saúde, os entrevistados não se mostram plenamente satisfeitos com a experiência no que 
se refere a obtenção de informações sobre saúde. Isso chama atenção para a qualidade da relação entre os profissionais e os usuários dos serviços, na prestação de informações e esclarecimentos sobre procedimentos ou outros assuntos que sejam de interesse do paciente.

Um dos princípios que devem nortear as ações e serviços do SUS no âmbito da atenção à saúde do adolescente e do jovem é o direito à informação. Assim, os profissionais de saúde são obrigados a informar, em linguagem compatível com a compreensão do usuário e com seu grau de instrução, informações sobre o estado de saúde do paciente, além dos meios existentes e possíveis para a sua manutenção ou recuperação (BRASIL, 2007b)

Os adolescentes relataram confiar em algumas informações recebidas sobre saúde, mas apresentaram certa criticidade quanto à origem e confiabilidade das informações oriundas da internet:

"Eu gosto da internet, mas não é tão confiante, às vezes a notícia pode ser falsa. Eu acredito em quem publicou, mas é errado né? A informação também pode ser falsa". (E1)

"Tem muito boato do povo, na internet tem muita coisa falsa, mas eu ainda sou mais a internet" (E5)

"Tem várias pessoas que fazem gracinha com a saúde, tipo, postando naqueles vídeos de funk, falando bem assim...'que não tem que tomar vacina, senão aí vai piorar'. Ficam fazendo gracinha com saúde. Aí depois que elas ficam mal, não sabem porque fizeram aquilo lá". (E6)

As necessidades informacionais, o comportamento de busca, compreensão e o uso de informação variam em cada fase da vida do indivíduo. Mesmo fazendo frequente uso de meios de comunicação, e não indicando terem critérios de seleção das informações acessadas na internet (ressaltado na categoria II), os adolescentes apresentam um pensamento crítico em relação aos conteúdos recebidos e acessados, como as informações falsas que circulam livremente pela rede. O entrevistado E6 citou, inclusive, informações falsas que foram veiculadas a respeito da campanha de vacinação. No Brasil, no período das campanhas de vacinação contra a febre amarela, influenza H1N1 e HPV, houve uma grande divulgação de informações falsas sobre o assunto, o que despertou a preocupação das autoridades de saúde. 
Os familiares foram citados como fontes seguras, que são consultadas para averiguar se determinadas informações publicadas são verdadeiras ou não.

\section{Categoria V: Autoavaliação do nível de conhecimento sobre saúde}

Quatro estudantes confirmaram a necessidade de ter acesso a mais informações, mas alguns adolescentes relataram ausência de interesse pelo assunto.

"Não tão bem informada. Eu queria ser mais informada, mas não sou. Às vezes eu nem procuro tanto saber o que é" (E1)

"Sou desinformado. Saúde não me interessa. Por que saúde é (...)não sei explicar porque não me interessa. Não faz sentido saber sobre saúde quando não se está doente. Só em caso de emergência. Quando você está doente, você se preocupa com isso (...) às vezes né? Só de vez em quando. Mas sei lá (...) também não é bom pra mim ser desinformado sobre saúde" (E4)

"Não corro atrás desse trem, de saúde. Não sou interessada mesmo não. Só procuro mesmo saber quando tá precisando mesmo" (E5)

Novamente observa-se que predomina uma percepção de saúde a partir de um conceito patológico, em que a saúde é ameaçada quando o corpo está enfermo, não considerando os demais aspectos relacionados a saúde.

Chama atenção a pouca relevância dada ao tema saúde por alguns entrevistados, ainda que pesquisas indiquem que a saúde do adolescente brasileiro requer cuidado. Entre outros dados, o Estudo de Riscos Cardiovasculares em Adolescentes (ERICA) realizado de 2013 a 2014, mostrou que 24,0\% dos adolescentes brasileiros que frequentam escolas em municípios com mais de 100 mil habitantes estão com pressão arterial elevada (pré-hipertensão ou hipertensão) e 25,0\% estão com excesso de peso. Cerca de $10,0 \%$ dos adolescentes observados no ERICA foram classificados como hipertensos (SICHIERI; CARDOSO, 2016).

Em relação aos temas que os alunos gostariam de obter mais informações, apenas dois entrevistados citaram hábitos alimentares e sexualidade. Quatro entrevistados não souberam responder. 
Inicialmente, este estudo tinha como ideia de amostra de entrevistados, 25 estudantes do 9‥ ano, adolescentes voluntários. Porém, a amostra ficou reduzida a 6 adolescentes. Esta redução de entrevistados, entende-se como uma limitação não apenas deste estudo, mas quando se trata de uma pesquisa qualitativa, onde as pessoas que fazem parte da amostra, se excluem do processo.

Contudo, conclui-se que, os adolescentes que fizeram parte desta pesquisa, apresentam uma compreensão de saúde pautada em um modelo biomédico, que pode ser constatada por meio da expressão de falas que asseveram que saúde está relacionada a ausência de doenças. A maioria dos adolescentes avaliou o próprio conhecimento sobre saúde como insuficiente. Situação compreensível, tendo em vista que as próprias fontes de informação podem ser questionadas quanto à sua veracidade científica.

As fontes de informação buscadas pelos adolescentes são: a escola, familiares, amigos, profissionais de saúde e meios de comunicação, como TV e Internet. Os familiares despertam grande confiança.

O ambiente escolar é percebido como propício pelos adolescentes na realização de ações de saúde. Para a melhoria da compreensão sobre o que é saúde, pelos adolescentes, sugere-se a realização de ações de Educação em Saúde, que envolvam os profissionais da Escola Municipal e da UBS de referência, no sentido de explorar as muitas dimensões que compõem a saúde a partir da perspectiva dos Determinantes Sociais em Saúde, e que essas possam ser esclarecidas e discutidas no interior da escola.

\section{REFERÉNCIAS}

ARAUJO, Inesita Soares de; CARDOSO, Janine Miranda. Comunicação e Saúde. Rio de Janeiro: Editora Fiocruz, 2007. 152 p.

BARDIN, Laurence. Análise de conteúdo. São Paulo: Edições 70, 2011. 223 p.

BRAGA, Renê Morais da Costa. A indústria das fake news e o discurso de ódio. In: PEREIRA, Rodolfo Viana (Org.). Direitos políticos, liberdade de expressão e discurso de ódio. v 1. Belo Horizonte: IDDE, 2018. p. 203-220. Disponível em:< http://www.idde.com.br/publicacoes/materiais/\%20a-industria-das-fake-news-e-o-discursode-odio/>. Acesso em: 20 abr. 2018. 
BRASIL. Estatuto da juventude : atos internacionais e normas correlatas. Brasília: Senado Federal, Coordenação de Edições Técnicas, 2013a. 103 p. Disponível em:< https://www2.senado.leg.br/bdsf/bitstream/handle/id/509232/001032616.pdf >.Acesso em: 24 out. 2018.

Diretrizes nacionais para a atenção integral à saúde de adolescentes e jovens na promoção, proteção e recuperação da saúde. Brasília: Ministério da Saúde, 2010. Disponível em: < http://bvsms.saude.gov.br/bvs/publicacoes/diretrizes_nacionais_atencao_saude_adolesce ntes_jovens_promocao_saude.pdf>. Acesso: em 18 mar.2018. 132 p.

Escolas Promotoras de Saúde: experiências no Brasil. Ministério da Saúde, Organização Pan-Americana da Saúde.Brasília: Ministério da Saúde, 2007a. Disponível em: < http://bvsms.saude.gov.br/bvs/publicacoes/escolas_promotoras_saude_experiencias_bras il_p1.pdf>. Acesso em: 15 ago. 2017. 304 p.

Marco legal: saúde, um direito de adolescentes. Ministério da Saúde. Secretaria de Atenção à Saúde. Brasília: Editora do Ministério da Saúde, 2007b. Disponível em: < http://bvsms.saude.gov.br/bvs/publicacoes/07_0400_M.pdf>. Acesso em 27 out. 2018.

Relatório das oficinas de comunicação. Ministério da Saúde. Conselho Nacional de Saúde. - Brasília: Editora do Ministério da Saúde, 2006. Disponível em: < http://bvsms.saude.gov.br/bvs/publicacoes/relatorio_oficinas_comunicacao.pdf >. Acesso em: 10 set. $2018.104 \mathrm{p}$.

Lei no 8.069, de 13 de julho de 1990. Dispõe sobre o Estatuto da Criança e do Adolescente e dá outras providências. Presidência da República, Casa Civil, Subchefia para Assuntos Jurídicos, Brasília, DF, de 13 de julho. 1990.

GONDIM, Priscilla Santos et al . Acessibilidade dos adolescentes às fontes de informações sobre saúde sexual e reprodutiva. Rev. Bras. Crescimento Desenvolv. Humano, São Paulo, v. 25, n. 1, p. 50-53, 2015. Disponível em $<$ http://pepsic.bvsalud.org/scielo.php?script=sci_arttext\&pid=S0104$12822015000100006 \&$ Ing=pt\&nrm=iso $>$. Acesso em set. 2018.

GOSCH,Cristiane Scolari (org). Curso de extensão em promoção da saúde para gestores do SUS com enfoque no programa academia da saúde. Brasília: Fundação Universidade de Brasília, CEAD ,2013. Disponível em:< em:http://portalarquivos.saude.gov.br/images/pdf/2014/novembro/04/Livro-EaD---Promo---o-da-Sa--de---Academia-da-Sa--de.pdf>. Acesso em: 18 set.2017. 146 p.

NORONHA, Grace Peixoto. Sexualidade e fontes de informação entre adolescentes estudantes do Ensino Médio. Dissertação (Mestrado em Saúde Pública) - Universidade de São Paulo, São Paulo, 2009. Disponível em: < http://www.teses.usp.br/teses/disponiveis/6/6136/tde-26052010-144327/pt-br.php>. Acesso em 15 jan. 2018. 
PASTORE,Mariana. $80 \%$ dos internautas no Brasil usam internet para fazer buscas sobre saúde. Folha de São Paulo. Editoria Saúde. 05 jan, 2011. Disponível em: <

https://www1.folha.uol.com.br/fsp/saude/sd0501201102.htm>. Acesso em: 22 set. 2018

PESQUISA NACIONAL DE SAÚDE DO ESCOLAR 2015 / IBGE. Coordenação de População e Indicadores Sociais. Rio de Janeiro: IBGE, 2016. Disponível em: < https://biblioteca.ibge.gov.br/visualizacao/livros/liv97870.pdf>. Acesso em 20 jun. 2018. MINAYO, Maria Cecília de Souza (org.). Pesquisa Social. Teoria, método e criatividade. 18 ed. Petrópolis: Vozes, 2001.

SICHIERI, Rosely; CARDOSO Marly A. ERICA: Estudo dos Riscos Cardiovasculares em Adolescentes. Rev. Saúde Publica. 2016; 50 (supl. 1), 1s. Disponível em: < http://www.scielo.br/pdf/rsp/v50s1/pt_0034-8910-rsp-S015188787201605000 SUPL1ED.pdf>. Acesso em 10 jun. 2018.

SILVA, Carlos dos Santos; BODSTEIN, Regina Cele de Andrade. Referencial teórico sobre práticas intersetoriais em Promoção da Saúde na Escola. Ciênc. Saúde Coletiva, Rio de Janeiro, v. 21, n. 6, p. 1777-1788, junho, 2016. Disponível em:

$<$ http://www.scielo.br/scielo.php?script=sci_arttext\&pid=S1413$81232016000601777 \&$ Ing=en\&nrm=iso >. Acesso em mar. 2018.

SOUSA, Zaira Andressa Alves de; SILVA, Julyana Gall da; FERREIRA, Márcia de Assunção. Saberes e práticas de adolescentes sobre saúde: implicações para o estilo de vida e cuidado de si. Esc. Anna Nery. Rio de Janeiro, v. 18, n. 3, p. 400-406, set, 2014 . Disponível em: <http://www.scielo.br/scielo.php?script=sci_arttext\&pid=S1414$81452014000300400 \&$ Ing=en\&nrm=iso $>$. Acesso em: 21 mar. 2018.

VIEIRA, Roberta Peixoto et al . Participação de adolescentes na Estratégia Saúde da Família a partir da Estrutura Teórico-Metodológica de uma Participação Habilitadora. Rev. Latino-Am. Enfermagem, Ribeirão Preto, v.22, n. 2, p. 309-316, abr. 2014. Disponível em: <http://www.scielo.br/scielo.php?script=sci_arttext\&pid=S0104$11692014000200309 \&$ Ing=en\&nrm=iso>. Acesso em: 22 set. 2018.

XAVIER,Caco. Mídia e Saúde, Saúde na Mídia. In: Caderno mídia e saúde pública. SANTOS,Adriana (org.).Caderno mídia e saúde pública. Belo Horizonte: Escola de Saúde Publica/FUNED, 2006. Disponível em:< http://www.esp.mg.gov.br/wpcontent/uploads/2009/06/caderno_midia_e_saude_publica.pdf>. Acesso em: 10 out. 2017. 